\title{
PERFIL EPIDEMIOLÓGICO E DETERMINANTE SOCIAL DO COVID- 19 EM MACAPÁ, AMAPÁ, AMAZÔNIA, BRASIL
}

\section{ARTIGO ORIGINAL}

SILVA, Anderson Walter Costa $^{1}$, CUNHA, Arthur Arantes ${ }^{2}$, ALVES, Giovana Carvalho ${ }^{3}$, CORONA, Rodolfo Antônio ${ }^{4}$, DIAS, Claudio Alberto Gellis de Mattos ${ }^{5}$, NASSIRI, Reza ${ }^{6}$, VEDOVELLI, Silvana7, VILHENA, Tania Regina Ferreira ${ }^{8}$, FAVACHO, Veronica Batista Cambraia ${ }^{9}$, SOUSA, Josiany Ferreira ${ }^{10}$, ARAÚJO, Maria Helena Mendonça ${ }^{11}$, OLIVEIRA, Euzébio ${ }^{12}$, DENDASCK, Carla Viana ${ }^{13}$, FECURY, Amanda Alves ${ }^{14}$

SILVA, Anderson Walter Costa. Et al. Perfil epidemiológico e determinante social do COVID-19 em Macapá, Amapá, Amazônia, Brasil. Revista Científica Multidisciplinar Núcleo do Conhecimento. Ano 05, Ed. 04, Vol. 04, pp. 05-27. Abril de 2020. ISSN: 2448-0959, Link de acesso: https://www.nucleodoconhecimento.com.br/saude/covid-19-em-macapa,

DOI: 10.32749/nucleodoconhecimento.com.br/saude/covid-19-em-macapa

\footnotetext{
${ }^{1}$ Médico, Especialista em Gestão de Sistemas e Serviços de Saúde. Professor, preceptor e pesquisador do Curso de Medicina do Campus Macapá, Universidade Federal do Amapá (UNIFAP).

${ }^{2}$ Acadêmico do Curso de Medicina do Campus Macapá, Universidade Federal do Amapá (UNIFAP).

${ }^{3}$ Acadêmica do Curso de Medicina do Campus Macapá, Universidade Federal do Amapá (UNIFAP).

${ }^{4}$ Acadêmico do Curso de Medicina do Campus Macapá, Universidade Federal do Amapá (UNIFAP).

${ }^{5}$ Biólogo, Doutor em Teoria e Pesquisa do Comportamento, Professor e pesquisador do Curso de Licenciatura em Química do Instituto de Ensino Básico, Técnico e tecnológico do Amapá (IFAP).

${ }^{6}$ Médico. Doutor em Hematologia, Especialista em Farmacologia Clínica com expertise em Saúde Global e Infecções Virais. Professor do Departamento de Farmacologia e Toxicologia, e Medicina da Família e Comunidade. Universidade Estadual de Michigan (MSU), Michigan, USA.

${ }^{7}$ Enfermeira. Secretária de Saúde do Município de Macapá AP (SESA AP).

${ }^{8}$ Enfermeira. Mestra em Ciências da Saúde. Secretaria Municipal de Saúde do Amapá (SESA AP).

${ }^{9}$ Enfermeira. Doutora em Ciências. Secretaria Municipal de Saúde do Amapá (SESA AP).

${ }^{10}$ Enfermeira. Secretaria Municipal de Saúde do Amapá (SESA AP).

${ }^{11}$ Médica, Mestra em Ensino e Ciências da Saúde, Professora, preceptora e pesquisadora do Curso de Medicina do Campus Macapá, Universidade Federal do Amapá (UNIFAP).

12 Biólogo, Doutor em Doenças Topicais, Professor e pesquisador do Curso de Educação Física da, Universidade Federal do Pará (UFPA).

13 Teóloga, Doutora em Psicanálise, pesquisadora do Centro de Pesquisa e Estudos Avançados- CEPA.

${ }^{14}$ Biomédica, Doutora em Doenças Topicais, Professora e pesquisadora do Curso de Medicina do Campus Macapá, Universidade Federal do Amapá (UNIFAP).
}

RC: 48443

Disponível em: https://www.nucleodoconhecimento.com.br/saude/covid-19-em$\underline{\text { macapa }}$ 


\section{RESUMO}

No final de dezembro de 2019, em Wuhan, China, surgiu uma nova variedade do Coronavírus, sendo declarado como uma emergência em saúde pública mundial pela Organização Mundial da Saúde (OMS). O tropismo pelas vias aéreas pode dever-se a expressão da enzima conversora de angiotensina 2 (ACE2). Na região da Amazônia Legal brasileira, até 22 de março de 2020, o Estado do Amazonas apresentou 26 casos confirmados; o Acre 11 casos; o Pará 04; Rondônia 03; Roraima, Tocantins, Maranhão e Mato Grosso 02 casos; e o Amapá apenas 01 caso confirmado. Este estudo visa quantificar e analisar os primeiras casos suspeitos e confirmados de COVID-19 em Macapá, Amapá, Amazônia, Brasil. Trata-se de um estudo observacional, retrospectivo e quantitativo, referente ao perfil dos 108 primeiros casos suspeitos notificados em Macapá, entre 13 de março de 2020 e 21 de março de 2020, e aos cálculos de incidência de COVID-19 nas 26 capitais brasileiras e Brasília, Distrito Federal, entre 26 de Fevereiro de 2020 e 26 de Março de 2020. Os estudos realizados podem revelar um padrão próprio de disseminação do vírus, o que contribuiria para o planejamento e para a implementação de medidas de controle e de vigilância epidemiológica mais efetivas.

Palavras-chave: COVID 19, ACE2, coronavírus, pandemia.

\section{INTRODUÇÃO}

No final de dezembro de 2019, em Wuhan, China, surgiu uma nova variedade do Coronavírus, capaz de produzir quadro de Síndrome Respiratória Aguda Grave (SRAG), sendo declarado como uma emergência em saúde pública mundial pela Organização Mundial da Saúde. Esse vírus, denominado SARS-CoV-2, produz uma doença classificada como COVID-19 (CID-10-B34.2) (BRASIL, 2020a; WHO, 2020a; MCINTOSH, 2020). O SARS-CoV-2 pertence ao gênero betaCovs, da subfamília Orthocoronavirinae, da família Coronaviridae. É um vírus envelopado (uma membrana lipídica dupla com proteínas nela inseridas) de fita única de RNA, que 
possui a forma de coroa, devido as glicoproteínas em forma de espinhos, presentes em seu envelope (CASCELLA et al., 2020; VELAVAN et al., 2020).

Os sintomas mais comuns, porém inespecíficos, relacionados à infecção por esse vírus são: febre (83,0\%-99,0\%), tosse seca $(59,4 \%-82,0 \%)$, dispneia $(55,0 \%)$, fadiga (cansaço) $(38,1 \%)$, dor de garganta $(13,9 \%)$, cefaleia (dor de cabeça) $(13,6 \%)$ e diarreia (3,7\%) (BRASIL, 2020a; LI et al., 2020; WHO, 2020a). Esses sintomas podem aparecer em consonância com o tempo de incubação do vírus, em média, de 5 a 6 dias após a infecção (WHO, 2020a; ROTHAN et al., 2020).

O tropismo pelas vias aéreas pode dever-se a expressão da enzima conversora de angiotensina 2 (ACE2) no parênquima pulmonar, no epitélio das vias aéreas humanas e no endotélio vascular. A ACE2 é uma das principais mediadoras da entrada do vírus nas células do hospedeiro humano, atuando como um receptor para entrada do patógeno. Todavia, esse mecanismo não é suficiente para explicar o acometimento de linhagens de células humanas, que não expressavam a ACE2, mas foram infectadas (LI et al., 2020; LI et al., 2003; ROTHAN et al., 2020).

Uma característica do SARS-CoV-2, que contribuiu para que ele se tornasse um problema de saúde pública mundial, é sua alta taxa/potencial de transmissão, que ocorre por meio de fômites (materiais inanimados contaminados que servem de veículo para transmissão) e de gotículas respiratórias de tosse e/ou de espirro (transmissão por aerossol). Esta transmissão pode acontecer, dependendo da concentração de partículas virais no ambiente, tendo sido demonstrada viabilidade viral em dispersão aerossol por três horas ou mais. A via oro-fecal não parece efetiva, embora vírus viáveis tenham sido encontrados em alguns casos (CASCELLA, et al., 2020; DOREMALEN, et al., 2020; WHO, 2020a). O SARS-Cov-2 é a terceira ameaça global à saúde pública após o SARS e o MERS (NASSIRI, 2020).

Segundo o Centro de Operações de Emergências em Saúde Pública (COE-nCoV) as medidas básicas de prevenção são: lavar as mãos com frequência usando 
sabonete e água (por ao menos 20 segundos); na impossibilidade de usar água e sabonete, utilizar como alternativa alcool $70 \%$ ou um desinfetante a base de álcool; evitar toques na face, olhos e boca com mãos não lavadas; cobrir com lenço de papel boca e nariz ao espirrar ou tossir (e depois descartar o lenço); limpar objetos e superfícies tocados(as) com frequência (maçaneta, telefone celular, controle remoto); evitar contato com pessoas doentes (afastamento); e ficar em casa se estiver apresentando sintomas, mesmo que de gripe comum (BRASIL, 2020b).

O início do protocolo de tratamento da pneumonia por COVID (2019-nCoV) depende do reconhecimento precoce dos sinais, monitorados de forma contínua, levando em consideração as manifestações clinicas e as características gerais da infecção. Para tanto o Ministério da Saúde do Brasil criou um protocolo de tratamento (BRASIL, 2020b; BRASIL, 2020c).

A alta taxa/potencial de transmissão, aliada a atual inexistência de um medicamento antiviral específico para tratamento (BRASIL, 2020c), propiciou os 55.924 casos de COVID-19 confirmados na China, até 20 de fevereiro de 2020 (WHO, 2020b). A letalidade, de $44.672(79,9 \%)$ variou de acordo com a faixa etária, sendo de 0,2\% em pacientes de 10-39 anos e podendo chegar a 8,0\% em pacientes de 70-79 anos e a $14,8 \%$ em pacientes com idade $\geq 80$ anos, o grupo mais vulnerável. A variação da taxa de letalidade pode ser justificada pelos fatores de risco associados, como as histórico de doenças cardiovasculares prévias, a diabetes, a hipertensão, a doença respiratória crônica e o câncer (GALLASCH et al., 2020; ZHANG et al., 2020; WHO, 2020a). Já na Itália, segundo país com maior acometimento, até 20 de março de 2020, foram confirmados 53.578 casos de COVID-19, com 4.827 óbitos, o que resultou em uma de letalidade geral de 9,0\% (WHO, 2020b).

No Brasil, o primeiro caso de COVID-19 foi confirmado em 26 de fevereiro de 2020 (WHO, 2020c) e até 22 de março de 2020 foram confirmados 1.546 casos e 25 óbitos (22 no estado de São Paulo e 03 no estado do Rio de Janeiro) pelo COVID19. Deste total, $926(59,9 \%)$ foram registrados na região Sudeste; $231(14,9 \%)$ na 
região Nordeste; 179 (11,6\%) na região Sul; 161 (10,4\%) na região Centro-Oeste; e $49(3,2 \%)$ na região Norte do país (BRASIL, 2020d).

$\mathrm{Na}$ região Norte, até a mesma data, o Estado do Amazonas apresentou 26 casos confirmados; o Acre 11 casos; o Pará 04; Rondônia 03; Roraima e Tocantins 02 casos; e o Amapá apenas 01 caso confirmado (BRASIL, 2020d).

Diante do aumento exponencial de casos da COVID-19 e do estabelecimento dos desafios para a saúde pública brasileira, estudos epidemiológicos que avaliem as especificidades da população envolvida e analisem a influência de fatores sociais nas taxas de transmissibilidade do vírus são de extrema importância e de necessidade sanitária (LIPSITCH et al., 2020).

\section{OBJETIVO}

Quantificação e análise do índice inicial de casos suspeitos e subsequentemente confirmados de COVID-19 em Macapá, Amapá, Amazônia, Brasil.

Analisar a incidência de casos confirmados de COVID-19 nas capitais situadas na Amazônia Legal em comparação com as demais capitais brasileiras e correlacionar com indicadores socioeconômicos, sociodemográficos e de saúde.

\section{MATERIAIS E MÉTODOS}

\section{PERÍODOS TEMPORAIS DO ESTUDO}

Trata-se de um estudo observacional, retrospectivo e quantitativo. Este estudo possui dois períodos temporais. Um deles, referente ao perfil dos 108 primeiros casos suspeitos notificados em Macapá, limita-se entre 13 de março de 2020, data da notificação do primeiro caso suspeito no Brasil (WHO, 2020c), e 21 de março de 2020, devido a Portaria n 454, do Ministério da Saúde (MS), que declarou estado de transmissão comunitária no Brasil (BRASIL, 2020e). Ressalta-se que casos 
notificados até 21 de março podem ter sua confirmação/descarte alguns dias após a notificação, devido o prazo de análise laboratorial.

O outro período temporal deste estudo, referente aos cálculos de incidência de COVID-19 nas 26 capitais brasileiras e Brasília, Distrito Federal, limita-se entre 26 de Fevereiro de 2020, data do primeiro caso confirmado no Brasil (WHO, 2020c), e 26 de Março de 2020, um mês após a confirmação do primeiro caso.

\section{DADOS, VARIÁVEIS E MÉTODOS DE CÁLCULO}

Este estudo utilizou-se de dados secundários. Os dados referentes ao perfil dos primeiros 108 casos suspeitos em Macapá, foram extraídos do banco de dados e informações agregadas desenvolvido pela Secretaria de Saúde do Município de Macapá, Amapá, Brasil.

Os dados de população, por faixa, do município de Macapá foram estimados a partir da Pesquisa Nacional por Amostra de Domicílios Contínua 2016-2018 (BRASIL, 2018a), com referência na população de Macapá em 2019 (BRASIL, 2020f). Esses dados de população foram utilizados no cálculo do Coeficiente de Casos Suspeitos (CCS) por faixa etária, independente de sexo, que foi calculado segundo a fórmula:

$$
\text { Coeficiente }(\mathrm{CCS})=\frac{\text { Número de casos suspeitos em determinada faixa etária } \times 100.000}{\text { Quantitativo populacional estimado da faixa etária referida }}
$$

Os quantitativos de casos confirmados de COVID-19, utilizados para calcular as incidências (por 100.000 pessoas) nas capitais brasileiras, até 26 de Março de 2020, foram extraídos do Mapa do Coronavírus (2020), que fornece dados agregados oficiais e atualizados, fornecidos pelas Secretarias de Estaduais de Saúde, de todos os municípios brasileiros com casos confirmados. Já os dados populacionais, utilizados no cálculo das incidências, foram extraídos do IBGE - Cidades e Estados (BRASIL, 2020f). O método de cálculo das incidências foi: 


\section{Incidência $=\frac{\text { Número de casos confirmados em determina capital } \times 100.000}{\text { Quantitativo populacional da capital referida, no ano de } 2019}$}

Os indicadores socioeconômicos de Índice de Desenvolvimento Humano (IDH) e porcentagem de pessoas pobres foram extraídos da plataforma Atlas Brasil (2020). Os quantitativos de estabelecimentos de saúde (período de referência: outubro de 2015) foram extraídos da plataforma DATASUS (BRASIL, 2020g) do Ministério da Saúde (MS). Já a densidade demográfica (DD) foi calculada utilizando informações recentes, visto que a última oficial é referente ao Censo de 2010 do IBGE. Assim, os dados de área territorial da capital (ano de referência: 2018) e população da capital (ano de referência: 2019) foram utilizados para calcular a DD (DD = população da capital em 2019 / área da capital em quilômetros quadrados em 2018).

\section{CRITÉRIOS DE INCLUSÃO E EXCLUSÃO DE DADOS}

Para a análise do sexo dos 108 primeiros registros foram incluídos todos os casos suspeitos $(n=108)$; do tempo entre o primeiro sinal/sintoma e a notificação do caso foram excluídos oito casos, sendo cinco masculinos e três femininos $(n=100)$; da idade, país de residência, quantitativo de sinais/sintomas e morbidades prévias foram excluídos apenas um caso, do sexo feminino ( $n=107)$; quanto a viagem para fora do Brasil e contato com caso suspeito ou confirmado foram excluídos três casos, todos femininos $(n=105)$; quanto a unidade de saúde notificadora foram excluídos 12 casos ( $n=96)$; quanto a ocupação foram excluídos 3 casos $(n=105)$. Todas as exclusões foram devidas a inexistência da informação ("ignorada"). Os "outliers" (valores aberrantes) não foram excluídos da análise.

$\mathrm{Na}$ análise das incidências e das correlações foram incluídas todas as 26 capitais das Unidades Federativas brasileiras e Brasília, capital federal. As capitais foram divididas em dois grupos, sendo um deles composto pelas capitais brasileiras situadas da região da Amazônia Legal brasileira (Belém, Boa Vista, Cuiabá, Macapá, Manaus, Palmas, Porto Velho, Rio Branco e São Luís) (BRASIL, 2014) e o outro 
pelas 17 capitais restantes mais a capital federal. Foram incluídos, para o cálculo da incidência, o quantitativo total de casos confirmados até as 21 horas e 06 minutos do dia 26 de março de 2020. Os "outliers" não foram excluídos da análise.

\section{ANÁLISE ESTATÍSTICA}

Os dados foram organizados, tabulados e analisados por meio do software Microsoft Excel ${ }^{\circledR} 2016$, do software OriginPro ${ }^{\circledR}$ versão 8.0724 e do software Statistical Package for the Social Sciences ${ }^{\circledR}$ versão 20.0. Ressalta-se que o software OriginPro ${ }^{\circledR}$ utilizado não aceitava a inserção, nos gráficos, do acento agudo.

A distribuição dos dados, quando pertinente, foi testada por meio dos testes Kolmogorov-Smirnov e Shapiro-Wilk. A escolha do teste foi feita de acordo com o tamanho amostral (TORMAN et al., 2012). A homogeneidade de variância, quando pertinente, foi testada com o teste de Levene baseado na média (LEVIN et al., 2018).

Para análise estatística dos 108 primeiros casos suspeitos foi utilizado o teste $t$ de Student para diferença de médias de amostras independentes ou o teste de $U$ de Mann-Whitney para diferença de medianas. Variáveis que não tiveram a hipótese de distribuição normal rejeitada e que apresentaram homogeneidade de variância foram testadas com o teste $t$, já as variáveis que não cumpriam esses requisitos foram testadas com o teste de Mann-Whitney (TORMAN et al., 2012). Analisou-se, comparando os sexos, a existência significativa de diferença de média ou mediana da idade (em anos), do intervalo de dias entre o primeiro sinal/sintoma até a data de notificação do caso suspeito e do quantitativo de sinais/sintomas apresentados. $O$ nível de significância foi $p$-valor $\leq 0,05$.

A análise de diferença da incidência entre as capitais situadas na região da Amazônia Legal brasileira $(n=9)$ e as demais capitais brasileiras $(n=18)$ foi feita sem levar em consideração a hipótese de distribuição normal, devido ao tamanho amostral menor que 10. Assim, procedeu-se para a alternativa não-paramétrica de 
análise, teste $U$ de Mann-Whitney. O nível de significância foi $p$-valor $\leq 0,05$ (LEVIN et al., 2018; TORMAN et al., 2012).

A hipótese de distribuição normal não foi rejeitada para as variáveis: Incidência das capitais brasileiras, IDH das capitais brasileiras, Porcentagens de pessoas pobres nas capitais brasileiras e Quantitativo de estabelecimentos de saúde nas capitais brasileiras. Assim, prosseguiu-se com o teste de correlação de Pearson (bivariada). Foram observadas as direções das correlações (positiva ou negativa) e a intensidade do coeficiente de correlação Pearson ( $r$ ). A intensidade (forte, moderada, fraca ou inexistente) é avaliada de acordo com valor de $r$ (LEVIN et al., 2018). O nível de significância adotado foi p-valor $\leq 0,05$.

Foram calculadas estatísticas descritivas de: média $(\bar{x})$, desvio padrão, mediana, mínimo e máximo.

\section{LIMITAÇÕES}

Entre as limitações deste estudo estão os casos que não deveriam ser notificados como suspeitos, pelas diretrizes do MS (BRASIL, 2020h), mas que compõem a amostra estudada. E a ausência de algumas informações no banco de dados (como profissão, data do primeiro sintoma e unidade de saúde notificadora), provavelmente devido ao preenchimento incorreto ou incompleto da ficha de notificação.

\section{ASPECTOS ÉTICOS}

O estudo utilizou dados secundários agregados, que não possibilitam a identificação individual, disponíveis no banco de dados da Secretaria Municipal de Saúde de Macapá, Amapá, Amazônia, Brasil, após anuência institucional. Além de informações disponíveis em endereços eletrônicos de acesso livre. Esta pesquisa seguiu os critérios das Resoluções número 466/2012 e número 510/2016, do Conselho Nacional de Ética em Pesquisa (CONEP) brasileiro. 


\section{RESULTADOS}

\section{ANÁLISE DOS 108 PRIMEIROS CASOS SUSPEITOS EM MACAPÁ}

Dos 108 casos suspeitos analisados neste estudo, notificados entre 13 de março de 2020 e 21 de março de 2020, três $(2,78 \%)$ foram confirmados, através de análise molécular (RT PCR), com COVID-19. Sendo todos brasileiros, dois casos do sexo feminino $(66,66 \%)$ e um do masculino (33,33\%). A idade média dos três casos foi de 36,3 anos. Os três $(100,0 \%)$ apresentaram febre, cefaleia, coriza. Dois $(66,66 \%)$ casos apresentaram tosse, produção de escarro e dificuldade de respirar. Todos os três realizaram viagem para fora do Brasil nos 14 dias anteriores a data de notificação. O tempo médio, dos três casos confirmado, entre a data de primeiro sinal/sintoma e a data de notificação foi de 3 dias.

O perfil do número total de casos suspeitos analisados foram os seguintes: $(n=107$; $99,07 \%)$, sexo feminino ( $n=59 ; 54,62 \%)$, faixa etária de $30-39$ anos $(n=29 ; 27,1 \%)$, sem morbidades prévias ( $n=78 ; 72,22 \%$ ) (Tabela 1 e Tabela 2, respectivamente). A idade geral (incluindo os dois sexos) média, em anos, foi $\bar{x}=34,2 \pm 14,9$, com mediana de 34 anos. Não houve diferença significante de média entre os sexos $(t=0,331 ; p=0,742)$ (Tabela 3). 
Tabela 1 Frequência e porcentagem, por sexo e faixa etária, dos casos suspeitos de COVID-19 analisados e Coeficiente por faixa etária. Macapá, Amapá, 13 a 21 de março de 2020.

\begin{tabular}{|c|c|c|c|c|c|c|}
\hline \multirow{2}{*}{$\begin{array}{c}\text { Faixa Etária } \\
\text { (anos) }\end{array}$} & \multirow{2}{*}{$\begin{array}{c}\text { Masculino } \\
\text { n (\%) }\end{array}$} & \multirow{2}{*}{$\begin{array}{c}\text { Feminino } \\
\mathbf{n}(\%) \\
\end{array}$} & \multicolumn{2}{|c|}{ Total } & \multirow{2}{*}{$\begin{array}{c}\text { *População } \\
\text { Estimada }\end{array}$} & \multirow{2}{*}{$\begin{array}{c}* * \text { Coeficiente } \\
\text { (por } 100.000 \text { pessoas) }\end{array}$} \\
\hline & & & $\mathbf{n}$ & $\%$ & & \\
\hline $0-19$ & $7(54 \%)$ & $6(46 \%)$ & 13 & $12,1 \%$ & 174.395 & 7,45 \\
\hline $20-29$ & $11(41 \%)$ & $16(59 \%)$ & 27 & $25,2 \%$ & 90.708 & 29,77 \\
\hline $30-39$ & $17(59 \%)$ & $12(41 \%)$ & 29 & $27,1 \%$ & 74.386 & 38,99 \\
\hline $40-49$ & $7(30 \%)$ & $16(70 \%)$ & 23 & $21,5 \%$ & 73.120 & 31,46 \\
\hline $50-59$ & $4(40 \%)$ & $6(60 \%)$ & 10 & $9,3 \%$ & 42.460 & 23,55 \\
\hline$\geq 60$ & $3(60 \%)$ & $2(40 \%)$ & 5 & $4,7 \%$ & 48.258 & 10,36 \\
\hline Total & $46(45 \%)$ & $57(55 \%)$ & $107 * * *$ & $100,0 \%$ & 503.327 & 21,26 \\
\hline
\end{tabular}

*População estimada por faixa etária, independente de sexo, para o município de Macapá; ${ }^{* *}$ Coeficiente $(C C S)=$ Total $n \times 100.000$ / População estimada para a faixa etária; ${ }^{* \star} U \mathrm{~m}$ caso feminino teve o item "Idade" ignorado.

Tabela 2 Frequência e porcentagem das morbidades prévias dos casos suspeitos de COVID-19 analisados. Macapá, Amapá, 13 a 21 de Março de 2020.

\begin{tabular}{|c|c|c|c|c|c|c|}
\hline \multirow{2}{*}{ Morbidade Prévia } & \multicolumn{2}{|c|}{ Masculino } & \multicolumn{2}{|c|}{ Feminino } & \multicolumn{2}{|c|}{ Total } \\
\hline & $\mathbf{n}$ & $\%$ & $\mathbf{n}$ & $\%$ & $\mathbf{n}$ & $\%$ \\
\hline $\begin{array}{l}\text { Doença cardiovascular, } \\
\text { incluindo hipertensão }\end{array}$ & 5 & $38,5 \%$ & 8 & $61,5 \%$ & 13 & $100,0 \%$ \\
\hline Doença pulmonar crônica & 3 & $50,0 \%$ & 3 & $50,0 \%$ & 6 & $100,0 \%$ \\
\hline Diabetes & 3 & $60,0 \%$ & 2 & $40,0 \%$ & 5 & $100,0 \%$ \\
\hline Doença hepática & 0 & $0,0 \%$ & 1 & $100,0 \%$ & 1 & $100,0 \%$ \\
\hline Neoplasia & 1 & $100,0 \%$ & 0 & $0,0 \%$ & 1 & $100,0 \%$ \\
\hline Imunodeficiência & 1 & $100,0 \%$ & 0 & $0,0 \%$ & 1 & $100,0 \%$ \\
\hline Doença neurologica crônica & 1 & $100,0 \%$ & 0 & $0,0 \%$ & 1 & $100,0 \%$ \\
\hline $\begin{array}{l}\text { Doença hepática e Doença } \\
\text { neuromuscular e Diabetes }\end{array}$ & 0 & $0,0 \%$ & 1 & $100,0 \%$ & 1 & $100,0 \%$ \\
\hline $\begin{array}{l}\text { Doença hepática e Doença } \\
\text { renal }\end{array}$ & 1 & $100,0 \%$ & 0 & $0,0 \%$ & 1 & $100,0 \%$ \\
\hline Total & 15 & $50,0 \%$ & 15 & $50,0 \%$ & 30 & $100,0 \%$ \\
\hline
\end{tabular}

RC: 48443

Disponível em: https://www.nucleodoconhecimento.com.br/saude/covid-19-emmacapa 
Tabela 3 Resultados dos testes estatísticos dos casos suspeitos de COVID-19 analisados. Macapá, Amapá, 13 a 21 de março de 2020.

\begin{tabular}{|c|c|c|c|c|c|c|c|c|c|c|}
\hline \multirow{3}{*}{ Variável } & \multicolumn{6}{|c|}{ Sexo } & \multicolumn{4}{|c|}{ p-valor Testes Estatísticos } \\
\hline & \multicolumn{3}{|c|}{ Masculino } & \multicolumn{3}{|c|}{ Feminino } & \multirow{2}{*}{$\begin{array}{c}\text { p-valor } \\
\text { normalidade } \\
\text { (Masc./Fem.) }\end{array}$} & \multirow{2}{*}{$\begin{array}{l}p \text {-valor } \\
\text { teste de } \\
\text { Levene }\end{array}$} & \multirow{2}{*}{$\begin{array}{c}\text { p-valor } \\
\text { teste } t \text { de } \\
\text { Student }\end{array}$} & \multirow{2}{*}{$\begin{array}{c}\text { p-valor U } \\
\text { Mann- } \\
\text { Whitney }\end{array}$} \\
\hline & Média $\pm D P$ & Mediana & Máx/Min. & Média $\pm \mathrm{DP}$ & Mediana & Máx/Min. & & & & \\
\hline Idade (em anos) & $33,6 \pm 15,0$ & 34,0 & $67 / 0,4$ & $34,6 \pm 14,9$ & 35,5 & $78 / 1$ & $0,64 / 0,51$ & 0,809 & 0,741 & -- \\
\hline $\begin{array}{l}\text { Quantitativo de } \\
\text { Sinais/Sintomas } \\
\text { apresentados }\end{array}$ & $5,8 \pm 2,7$ & 5,0 & $12 / 1$ & $6,6 \pm 4,0$ & 5,0 & $20 / 1$ & $0,44 / 0,053$ & 0,037 & -- & 0,488 \\
\hline $\begin{array}{l}\text { Intervalo de dias: } \\
1^{\circ} \text { sinal/sintoma } \\
\text { até data de } \\
\text { notificação }\end{array}$ & $3,4 \pm 2,6$ & 3,0 & $14 / 0$ & $3,5 \pm 3,0$ & 3,0 & $14 / 0$ & $0,00 / 0,004$ & 0,298 & - & 0,941 \\
\hline
\end{tabular}

DP: Desvio Padrão; Máx.: Máximo; Mín.: Mínimo.; Masc.: Masculino; Fem.: Feminino.

O cálculo do CCS, por meio da população por faixa etária no município de Macapá, demostrou que que a faixa etária de 30-39 anos apresentou o maior CCS, que foi de 38,99 casos suspeitos por 100.000 pessoas dessa faixa etária. De forma independente da idade, foram notificados 21,26 casos por 100.000 pessoas (Tabela 1).

Os sinais e sintomas mais frequentes, entre os casos suspeitos analisados, foram tosse, febre, coriza, dor de garganta, cefaleia, dificuldade de respirar, adinamia, dispneia/taquipneia e mialgia. Assim, $82,2 \%$ dos pacientes apresentaram tosse, $68,2 \%$ febre, $58,9 \%$ coriza, dor de garganta $(57,0 \%)$, cefaleia $(56,1 \%)$, dificuldade de respirar $(53,3 \%)$, adinamia $(36,4 \%)$, dispneia/taquipneia $(30,8 \%)$ e mialgia $(27,1 \%)$. A diferença de frequência e de porcentagem entres os sexos pode ser observada no gráfico $A$ e no gráfico $B$ (Figura 1).

RC: 48443

Disponível em: https://www.nucleodoconhecimento.com.br/saude/covid-19-em$\underline{\text { macapa }}$ 
Figura 1 Frequência e porcentagem dos sinais e sintomas apresentados pelos casos suspeitos de COVID-19 analisados, por sexo e geral. Macapá, 13 a 21 de março de 2020.
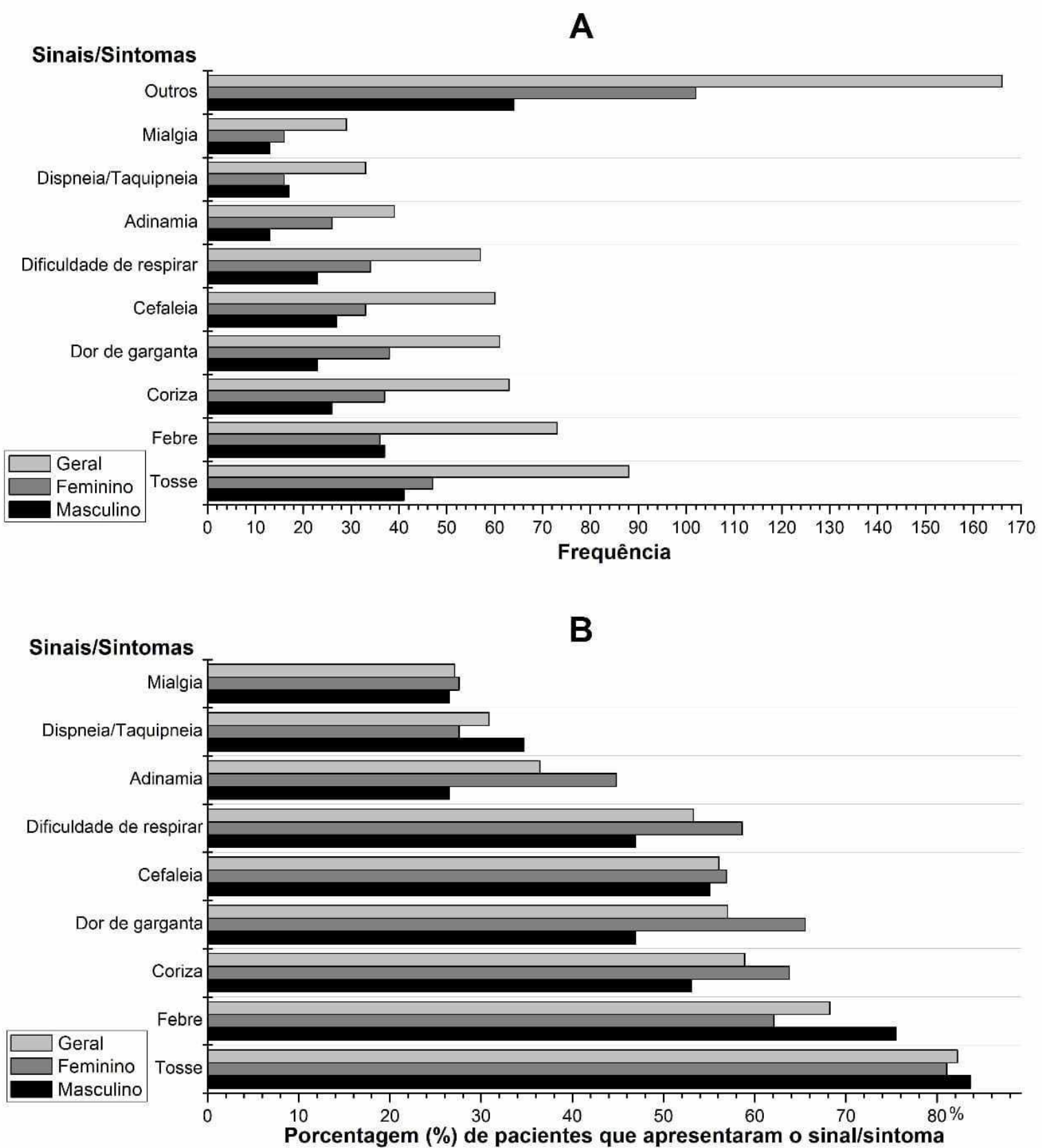

O quantitativo médio de sinais e sintomas, por caso suspeito analisado, foi de $\bar{x}$ $=6,3 \pm 3,5$. Entre os sexos, não houve diferença estatística significativa entre os quantitativos de sinais/sintomas apresentados $(U=1.311 ; p=0,488)$. O tempo, em

RC: 48443

Disponível em: https://www.nucleodoconhecimento.com.br/saude/covid-19-emmacapa 
dias, entre a data do primeiro sinal e sintoma e a data de notificação do caso suspeito foi de $\bar{x}=3,4 \pm 2,8$, com mediana de 3 dias. Não houve, entre os sexos, diferença significativa neste intervalo de tempo $(U=1.221,5 ; p=0,941)$ (Tabela 3).

Apenas 30 (28,04\%) indivíduos, entre os casos suspeitos analisados, apresentaram morbidades prévias, dos 107 casos analisados nesse quesito. A morbidade mais frequente foi "doença cardiovascular, incluindo hipertensão" ( $n=13 ; 43,33 \%$ ), seguido por "doença pulmonar crônica" ( $n=6 ; 20,00 \%)$ e por "diabetes" $(n=5 ; 16,66 \%)$ (Tabela 2).

A ocupação mais frequente foi "profissional da área da saúde" ( $n=9 ; 8,57 \%)$, sendo que 88 (83,81\%) casos, dos 105 analisados nesse quesito, foram referenciados como "outra". Aproximadamente $81,5 \%$ dos casos foram notificados por unidades públicas de saúde.

Dentre os 108 casos suspeitos, 18 pessoas $(16,16 \%)$ realizaram viagem para fora do Brasil, 16 (14,81\%) tiveram contato com caso suspeito ou confirmado de COVID19 e apenas 7 (6,5\%) foram expostas as essas duas condições. Essas duas condições foram ignoradas em apenas três dos 108 casos.

\section{ANÁLISE DA INCIDÊNCIA DE CASOS CONFIRMADOS DE COVID-19 EM MACAPÁ E DEMAIS CAPITAIS}

A incidência de casos confirmados de COVID-19 em Macapá, até 26 de março de 2020, um mês após o primeiro caso confirmado no Brasil, era de 0,397 casos por 100.000 pessoas. Macapá tinha a menor incidência dentre as capitais brasileiras. A média da incidência nas capitais nacionais $(n=27)$ era de $\bar{x}=2,94 \pm 2,19$ e mediana de 2,31. A capital nacional com maior incidência era Fortaleza, capital do Ceará, com 8,32 casos por 100.000 pessoas (Figura 2). 
Figura 2 Gráfico Boxplot que representa a incidência de COVID-19 nas capitais brasileiras, por grupo estudado. Capitais brasileiras, Brasil, de 26 de fevereiro de 2020 a 26 de março de 2020. (*“outlier”, representa a capital Rio Branco, Acre).

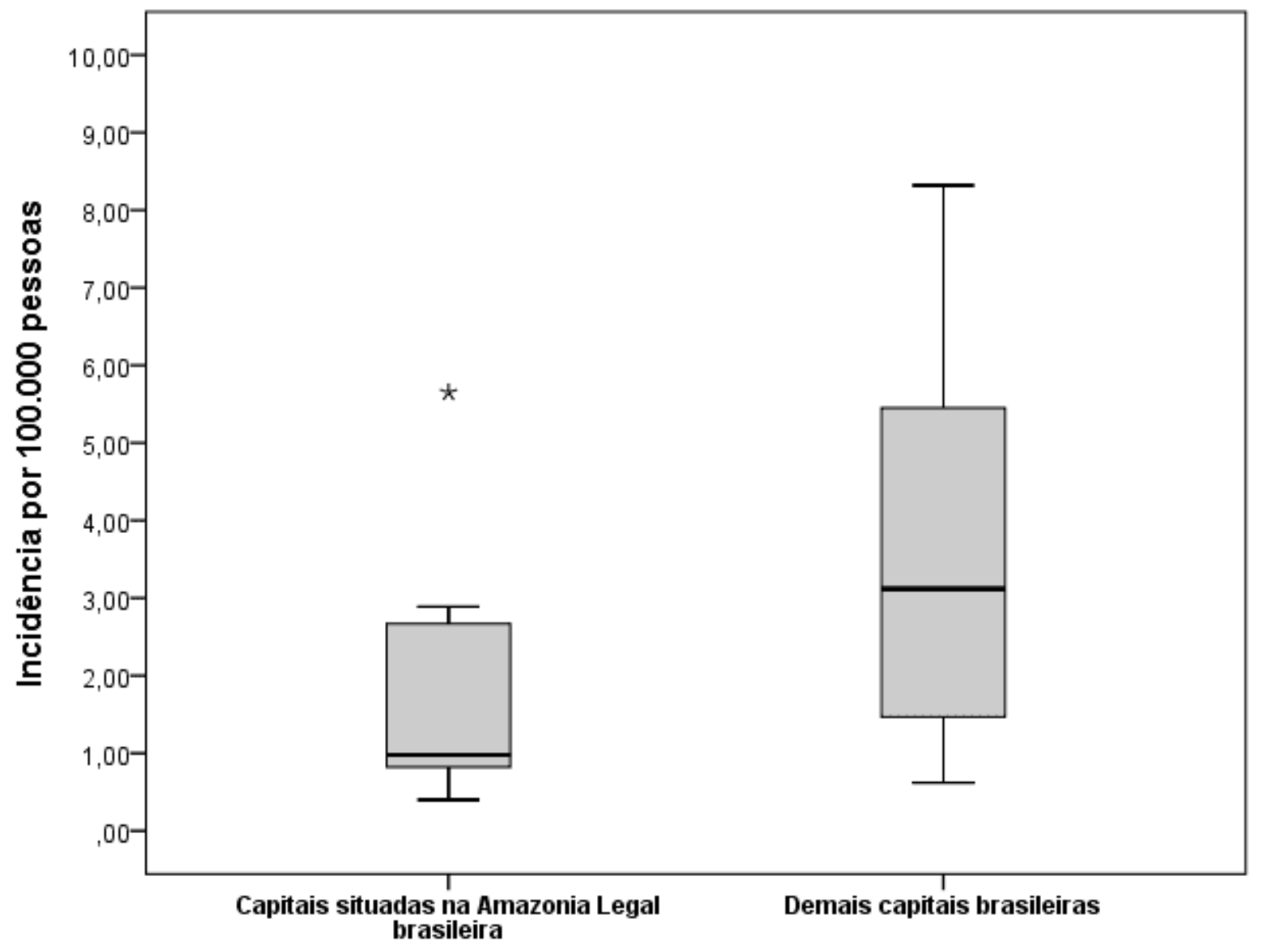

A incidência média das capitais situadas na Amazônia Legal brasileira era de $\bar{x}=1,86 \pm 1,70$ e mediana de 0,98 . A capital situada nessa região, com maior incidência, era Rio Branco, capital do Acre, com 5,65 casos por 100.000 pessoas (Figura 2). Houve diferença significante entre as incidências das capitais situadas na Amazônia Legal $(n=9 ; \bar{x}=1,86 \pm 1,70$; mediana $=0,98)$ e as incidências das demais capitais nacionais $(n=18 ; \bar{x}=3,48 \pm 2,24$; mediana $=3,12)(U=41,5 ; p=0,041)$.

As incidências nas capitais apresentaram correlação positiva e significativa com a densidade demográfica $(\mathrm{DD})$ das capitais $(r=0,416 ; \mathrm{p}=0,031)$, o quantitativo de 
estabelecimentos de saúde por capital por capital $(r=0,539 ; p=0,004)$ e com o IDH das capitais $(r=0,436 ; \mathrm{p}=0,023)$. E correlação negativa e significativa com a porcentagem de pessoas pobres por capital $(r=-0,409 ; p=0,034)$ (Figura 3 ).

Figura 3 Gráficos da correlação de Pearson entre a incidência e: a densidade demográfica; o quantitativo de estabelecimentos de saúde, o Índice de Desenvolvimento Humano e a porcentagem de pessoas pobres. (MCP: Macapá; $r$ : coeficiente

de correlação

de

Pearson).
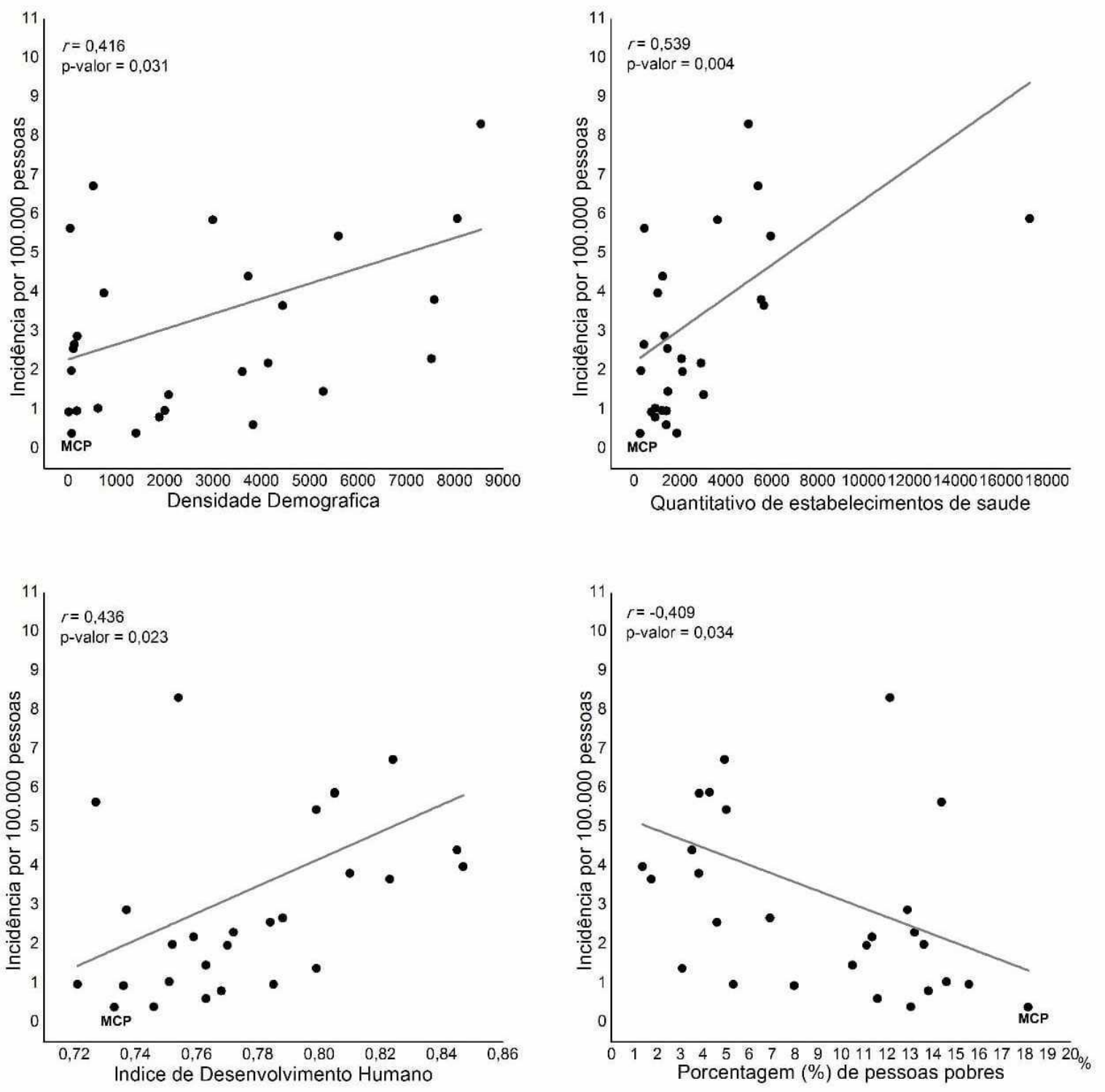

RC: 48443

Disponível em: https://www.nucleodoconhecimento.com.br/saude/covid-19-em$\underline{\text { macapa }}$ 


\section{DISCUSSÃO}

A porcentagem de casos confirmados $(n=3 ; 2,78 \%)$, dentre o total de 108 notificados como suspeitos no município de Macapá, foi superior quando comparada a de outros estados, como Mato Grosso e Minas Gerais, que, até 20 de Março de 2020, haviam confirmado, respectivamente, $1(0,81 \%)$ caso de 123 notificados e 38 $(0,92 \%)$ casos de 4.122 (SESAMT, 2020; SESAMG, 2020a). O perfil epidemiológico dos três casos confirmados com COVID-19 analisados no presente estudo é semelhante ao perfil dos quatro primeiros casos confirmados em Minas Gerais, quanto ao predomínio do sexo feminino e histórico de viagem para o exterior em todos os casos, mas há diferença de aproximadamente 10,5 anos na média das idades (SESAMG, 2020b). A média de dias entre o primeiro sinal e sintoma e a data de notificação dos três casos confirmados foi 0,4 dias menor do que a média geral. Isso reduz o tempo até o diagnóstico e o tratamento. reduz também o tempo em que o paciente infectado permanece em contato com outras pessoas com a possibilidade de contato e contágio (WHO, 2020a; ZHANG et al., 2020).

A predominância do sexo feminino $(n=59 ; 54,62 \%)$, no total de 108 casos suspeitos em Macapá, analisados neste estudo, corrobora com o perfil de casos suspeitos divulgado por SESAMG (2020c) em 03 de Março de 2020 (56,0\% feminino), com o perfil de casos suspeitos divulgado pela SESAMA (2020) em 19 de Março de 2020 (62,1\% feminino) e diverge pouco do perfil de casos suspeitos no Brasil, divulgado pelo Ministério da Saúde (MS) em 10 de Fevereiro de 2020 (53\% masculino) (BRASIL, 2020b). Essa predominância pode ser justificada pela leve maioria percentual de mulheres, em relação aos homens, em Macapá (BRASIL, 2018b) e por mulheres serem o principal público dos serviços de saúde no Brasil (LEVORATO et al., 2014).

A idade geral média dos suspeitos no presente estudo, $\bar{x}=34,2 \pm 14,9$ (mediana=34 anos), está próxima a do perfil em Minas Gerais, 33 anos (SESAMG, 2020c). No Estado do Ceará, até 19 de março de 2020, 42,7\% dos suspeitos eram do sexo feminino com idade entre 20 e 49 anos (SESACE, 2020). A semelhança entre as

RC: 48443

Disponível em: https://www.nucleodoconhecimento.com.br/saude/covid-19-emmacapa 
médias de idades dos sexos era esperada, tendo como referência o estudo de ZHANG et al., (2020), que descreveu proporção 0,99 masculino/1,0 feminino e predomínio de $89,8 \%$ na faixa etária de 30-79 anos dos casos em Wuhan, China.

A faixa etária, independente de sexo, com maior número de casos suspeitos notificados no presente estudo foi 30-39 anos, com $27,1 \%$ dos casos, bem próxima da porcentagem de 20-29 (25,2\%). Porcentagens semelhantes e com igual equilíbrio, para casos suspeitos, foram também descritas no Informe Epidemiológico, de 19 de março de 2020, do Estado do Rio Grande do Sul (SESARS, 2020). Essa semelhança entre a porcentagem simples das faixas etárias dos casos suspeitos pode ser explicada pela distribuição percentual da população, por faixa etária, de Macapá $(20-29=18,2 \% ; 30-39=14,5 \%)$ e do Estado do Rio Grande do Sul (20$29=14,0 \% ; 30-39=14,6 \%)$ (BRASIL, 2018a). E também pelo fato das pessoas no intervalo de idade entre 26 e 49 anos, no qual estão inclusas as duas faixas etárias 20-29 e 30-39, serem as que mais procuram serviços de saúde no Brasil (LEVORATO et al., 2014).

Ao analisar-se o CCS dessas duas faixas etárias, 38,99 (30-39 anos) e 29,77 (20-29 anos) casos por 100.000 pessoas, calculado neste estudo, é possível notar que o número de notificações por 100.000 pessoas é 31,0\% maior na faixa dos 30-39 anos em comparação com a de 20-29. Essa predominância do intervalo de 30-39 anos pode ser explicada por essa faixa etária está inclusa no intervalo de idade que mais procura serviços de saúde no Brasil (26-49 anos), e também pela possível relação entre a procura pelo serviço de saúde e a produtividade econômica laboral. No Estado do Amapá, a faixa etária mais produtiva, com maior número de trabalhadores (emprego formal), 41.365 (31,3\%), é a de 30-39 anos (BRASIL, 2018b; LEVORATO et al., 2014). A procura e acesso a saúde também é influenciado pela renda. Indivíduos com melhor situação econômica procuram mais e tem melhor acesso a serviços de saúde. No Brasil, a situação econômica das pessoas maiores de 30 anos é substancialmente melhor quando comparada as faixas etárias inferiores (BRASIL, 2018c; TRAVASSOS et al., 2006). 
Os sinais e sintomas predominantes investigados no presente estudo, tosse $(82,2 \%)$; febre $(68,2 \%)$; dor de garganta $(57,0 \%)$; dispneia/taquipneia $(30,8 \%)$, foram descritos como sendo os sinais e sintomas inespecíficos mais comuns nos casos confirmados de COVID-19 (BRASIL, 2020a; LI et al., 2020; WHO, 2020a). Houve, ainda, concordância com os sinais e sintomas dos pacientes suspeitos descritos por SESARS (2020) e por BRASIL (2020b). A maior discrepância foi observada na "dor de garganta", que apresentou $57,0 \%$ dos casos do atual estudo e comparado a $13,9 \%$ de 55.924 casos chineses confirmados (WHO, 2020a). Essa diferença pode ser devida ao fato de apenas $2,78 \%$ dos casos analisados no presente estudo serem confirmados, enquanto todos os casos descritos por WHO (2020a) possuem diagnóstico confirmado de COVID-19. Outra possibilidade seria a provável coinfecção por bactérias em alguns casos (ZHANG et al., 2020).

No atual estudo, o tempo médio, em dias, entre a data do primeiro sinal/sintoma, referido pelo paciente, e a data de notificação do caso suspeito foi $\bar{x}=3,4 \pm 2,8$. Em $50 \%$ dos casos notificados como suspeitos, a demora até a notificação foi maior ou igual a três dias (mediana=3). Isso indica que pacientes que foram considerados suspeitos para COVID-19 permaneceram, sintomáticos, em média 3,4 dias, tendo possível contato com demais pessoas. Segundo WHO (2020a) a transmissão da grande maioria dos casos se dá por pacientes sintomáticos, embora possa ocorrer, raramente, por paciente assintomático, como demonstrado por ROTHE et al. (2020).

As morbidades prévias apresentadas pelos casos suspeitos do presente estudo são similares as descritas para 20.812 pacientes chineses confirmados com COVID-19, no estudo de ZHANG et al. (2020), que descreveu a diabetes $(5,3 \%)$, a hipertensão arterial (12,8\%), outras doenças cardiovasculares $(4,2 \%)$ e as doenças pulmonares crônicas $(2,4 \%)$ como morbidades mais associadas a COVID-19, sendo a hipertensão e outras doenças cardiovasculares mais relacionadas ao desfecho desfavorável.

A única categoria profissional referida no presente estudo foi a da saúde $(n=9$; 8,57\%), que constitui um dos principais grupos de risco para COVID-19 (GALLASCH 
et al., 2020; ZHANG et al., 2020). Além disso, notou-se um elevado quantitativo de marcações como "outra" ( $n=88 ; 83,82 \%)$. Isso pode prejudicar a avaliação de outras possíveis profissões de risco, que talvez possam estar relacionadas a um maior risco de infecção (KOH, 2020; ZHANG et al., 2020;) A grande maioria dos casos suspeitos analisados neste estudo foram notificados pelo Sistema Único de Saúde (SUS), o que pode demonstra a importância e soberania desse sistema estatal, que atende a grande maioria da população brasileira de forma integral e gratuita (BRASIL, 2020f; VIANA et al., 2009).

Foi identificada correlação significante da incidência de COVID-19 com determinados indicadores. Ao menos no estágio inicial, até 26 de março de 2020, de disseminação do vírus, há uma correlação entre valores maiores de incidência da COVID-19 e a população que reside em cidades com bons indicadores de desenvolvimento social.

Entre a correlação analisada com associação positiva destaca-se à realizada com a densidade demográfica (DD). O maior número de casos de COVID-19/100.000 pessoas possui correlação com um maior número de pessoas ocupando uma mesma área em um determinado local. É importante destacar que a aglomeração de indivíduos facilita a propagação do vírus, visto que, as infecções em grupos familiares, bem como em profissionais de saúde, confirmam a ocorrência de transmissão humano a humano, majoritariamente por meio de contato próximo (READ et al., 2020; BRASIL, 2020i). Na China, as cidades mais densamente ocupadas, com maior número de voos diários, foram as mais afetadas (LAl et al., 2020; READ et al., 2020). Macapá, cidade com menor incidência apontada neste estudo, até fevereiro de 2020, possuía comunicação com voos comerciais diários e diretos apenas para Brasília, Distrito Federal, e Belém, Pará (BRASIL, 2020j).

As características populacionais relacionadas à COVID-19 ainda são pouco discutidas. Alguns estudos, como o realizado pela WHO (2020a), podem justificar o resultado dessa associação, pois evidenciam uma maior taxa de transmissibilidade em regiões de maior concentração populacional. Além disso, o MS propõe, de forma

RC: 48443

Disponível em: https://www.nucleodoconhecimento.com.br/saude/covid-19-emmacapa 
generalizada, que determinados surtos em áreas de alta densidade populacional apresentam maior chance de disseminação e representam, dessa forma, eventos com potencial para causar grande impacto na saúde pública (BRASIL, 2009).

Outro estudo de mapeamento e análise espacial, realizado na China, demonstrou que a distribuição dos casos de COVID-19 não foi aleatória. Os pontos de concentração de casos, no início da epidemia, estavam restritos a áreas de maior desenvolvimento econômico e densidade populacional. Tais fatores relacionam-se com o maior número de casos por proporcionarem maior mobilidade pendular, maior número de viagens e maior quantitativo de estabelecimentos de saúde habilitados a realizar o atendimento e diagnóstico (FAN et al., 2020a; LAI et al., 2020; OLIVEIRA et al., 2019; ZASLAVSKY et al., 2017).

Essas evidências corroboram e justificam os resultados encontrados no presente estudo, pois determinados indicadores sociodemográficos e de saúde apresentaram correlação positiva e significativa com a taxa de incidência da COVID-19 entre as capitais, ou seja a quantificação e análise dos casos registrados, entre 26 de Fevereiro e 26 de Março, no Brasil, demonstrou que as capitais que possuíam maior DD, maior Índice de Desenvolvimento Humano (IDH) e mais estabelecimentos de saúde apresentaram maiores taxas de incidência.

Bons indicadores sociais podem estar relacionados com um maior quantitativo de população flutuante, ou seja, àquela que está presente no território, em uma data específica, por um período de curta duração e em busca de diferentes atividades (BRASIL, 2011). Dessa forma, cidades com bons indicadores sociais e que ofertam possibilidades de turismo e de negócios podem apresentar maior incidência de infecções, especialmente as transmitidas via humano a humano, por disponibilizarem mais atrativos para essa população não residente sazonal, visto que, o indivíduo que compõe esse grupo é um portador potencial para a transmissão do vírus (FAN et al., 2020b). Um estudo de correlação, realizado por FAN et al. (2020b), avaliou a associação entre o quantitativo da população flutuante de Wuhan e o número de casos confirmados de COVID-19, obteve como resultado um 
coeficiente de correlação de 0,84 . Isso indica que quando uma região possui um número maior de pessoas não residentes mais casos confirmados surgirão nessa região.

A correlação negativa $(r=-0,409 ; p=0,034)$ entre a incidência da COVID-19 e a porcentagem de pessoas pobres por capital demostrou que quanto maior for o número de casos/100.000 pessoas, menor será a porcentagem de pessoas pobres residentes na capital. Essa constatação reafirma a existência da associação entre a incidência e o IDH, também observada no presente estudo.

A princípio, como um maior número de casos infectados exportados influencia diretamente na possibilidade de um maior quantitativo de casos secundários na comunidade, as capitais com maior porcentagem de pessoas pobres e por consequência que viajam menos podem apresentar menores incidências incialmente (KUCHARSKI et al., 2020; ROSA, 2006). No geral, essa população possui menos acesso a recursos educacionais, de informação e de saúde. Esses fatores podem dificultar o reconhecimento dos sinais/sintomas iniciais, e podem causar erros de identificação da COVID-19, além de limitar o acesso aos estabelecimentos de saúde, e por consequência, levando a subnotificação de diagnósticos (CAMPELLO et al., 2018).

Em concordância a essas observações, os resultados do presente estudo demonstraram, que Macapá é a capital que apresenta a menor incidência de COVID-19 por 100.000 pessoas após um mês de confirmação do primeiro caso no Brasil. E que, em consonância a isso, possui um dos menores IDHs e uma das menores DDs entre as capitais, o menor número de estabelecimentos de saúde do país entre as capitais, um número restrito de voos comerciais diários e a maior participação percentual de pessoas pobres entre todas as capitais nacionais (ATLAS BRASIL, 2020; BRASIL, 2020g; BRASIL, 2020j).

A incidência até 26 de março de 2020, no grupo de capitais da região da Amazônia Legal Brasileira $(n=9 ; \bar{x}=1,86 \pm 1,70$; mediana $=0,98)$, foi significativamente menor 
$(\mathrm{U}=41,5 ; \mathrm{p}=0,041)$ do que a de $\mathrm{o}$ grupo de outras capitais brasileiras $(\mathrm{n}=18 ; \bar{x}=$ $3,48 \pm 2,24$; mediana $=3,12$ ). Essa diferença pode dever-se ao isolamento socioespacial da Amazônia Legal, em relação ao restante do Brasil, descrito por VIANA et al. (2009). Um exemplo desse isolamento é a capital Macapá, na qual vivem $59,5 \%$ da população do Amapá, que não está conectada por terra ao resto do país (BRASIL, 2020f; DRUMMOND, 2000) e apresentou, neste estudo, a menor incidência $(0,397)$ de COVID-19 entre as capitais brasileiras.

Essa diferença na incidência do COVID-19 pode, além do isolamento socioespacial, estar relacionada a fatores climatológicos e urbanos da região amazônica, como alta umidade relativa e densidade demográfica (BRASIL 2020f; SILVA et al., 2013; WANG et al., 2020).

A princípio, os grandes centros urbanos da Amazônia brasileira apresentam histórico de epidemias de doenças virais transmitidas por mosquitos, como Zika e Febre Amarela. Todavia, os fatores climáticos do ecossistema amazônico que atuam sustentando a transmissão endêmica e/ou surgimento de ondas epidêmicas, por propiciar a reprodução dos mosquitos (FARIA et al., 2018; GIOVANETTI et al., 2020), podem desfavorecer a transmissão do COVID-19 na Amazônia.

Nos estudos in vitro de SILVA et al. (2013), de WANG et al. (2020) e de KAMPF et al., (2020), umidades relativas do ar elevadas estão de forma consistente relacionados a menor viabilidade de vírus envelopados causadores de doenças respiratórias, como o coronavírus. Isso pode dever-se a menor estabilidade viral em temperaturas mais altas e pelas gotículas respiratórias permanecerem menos tempo suspensas no ar com alta umidade (WANG et al., 2020). Já os resultados de OLIVEIROS et al. (2020) demonstraram que o número de casos de COVID-19, em modelo de regressão linear, sofreu apenas $18,0 \%$ de influência devido desses fatores climáticos. Enquanto a densidade populacional, transporte urbano, aspectos culturais, políticas de saúde pública e medidas de afastamento influenciam $82,0 \%$. 
Isso demostra que, possivelmente, apenas fatores climáticos não serão suficientes para conter o aumento do número de casos, sendo necessárias outras medidas, como o afastamento social, decretado pelo governo estadual em algumas unidades federativas da Amazônia Legal brasileira, como o Amapá (AP, 2020; RIPAP, 2020). $\mathrm{Na}$ ausência de vacinas ou antivirais eficazes, medidas como afastamento social, tem potencial para reduzir a excentricidade da curva de incidência da COVID-19, achatando seu pico e diminuindo a sobrecarga aguda no sistema de saúde. Sendo de essencial importância que as autoridades governamentais estejam atentas aos alertas epidemiológicos e ao que a comunidade científica tem a contribuir (HAFFAJEE et al., 2020; PREM et al., 2020; RIPAP, 2020; WU et al., 2020).

\section{CONCLUSÃO}

O perfil dos casos suspeitos, descrito neste estudo, é similar ao perfil de casos suspeitos e até mesmo, em alguns pontos, do perfil de casos confirmados na literatura científica, embora o quantitativo de estudos de perfil de casos suspeitos seja, atualmente, restrito. Localidades como Macapá, que apresentam características sociais, geográficas e econômicas particulares, podem revelar um padrão próprio de disseminação da COVID-19, o que torna interessante um contínuo e rigoroso acompanhamento do perfil epidemiológico dos casos.

Macapá, quando comparada a outras localidades brasileiras, possui uma taxa percentual melhor quanto as opções adotadas para o combate à virose. No entanto, a coordenação da notificação de casos pode ser otimizada por uma comunicação eficaz entre várias partes interessadas, incluindo instituições de saúde e sociedades profissionais de saúde.

O papel do governo na educação do público sobre a conscientização do COVID19 é crítico na redução do ônus da doença. Além disso, o registro da ocupação do caso notificado pode ser melhorado, incluindo, por exemplo, motoboys, correios e servidores de segurança pública, que provavelmente terão mais exposição em comparação com outros profissionais 
Mais de $80,0 \%$ dos casos analisados foram notificados por unidades de saúde públicas. Isso demostra a importância de um sistema estatal robusto de saúde, que pode fazer a diferença na contenção da epidemia de COVID-19, tanto em Macapá quanto na Amazônia brasileira e no resto do país.

A correlação entre a incidência de COVID-19 e os indicadores sociais, sociodemográficos e de saúde, infere que as capitais com maior desenvolvimento econômico, populacional e de saúde foram as mais acometidas pelo coronavírus depois de um mês do registro do primeiro caso no Brasil. Tal constatação deve-se, principalmente, pelo maior fluxo de viajantes. Diante disso, medidas restritivas de mobilidade populacional, assim como de afastamento social, podem ser mais efetivas se direcionadas para as capitais com grande fluxo de pessoas.

As características particulares de Macapá, apontadas neste estudo, retardaram, a princípio, a transmissibilidade do coronavírus na capital amapaense. $O$ fato de Macapá estar afastada do principal eixo socioeconômico nacional, não possuir vias terrestres de comunicação com outras grandes cidades e ter número reduzido de voos para outras cidades, parece ter contribuído para a discreta taxa de incidência nessa localidade, até 26 de março de 2020. Macapá é a capital brasileira com o menor número de estabelecimentos de saúde. Isso certamente levanta questões sobre transmissões assintomáticas, já que a infraestrutura de saúde pública nesta cidade enfrenta algumas limitações. Todavia, a taxa percentual de diagnósticos descrita neste estudo para Macapá permanece maior que a de alguns estados brasileiros com indicadores socioeconômicos e em saúde melhores. Provavelmente porque municípios de interior possuem menor aparato estatal de saúde e administrativo. Um maior aparato estatal poderia ser capaz de influenciar diretamente em condutas e protocolos tomados em unidades de saúde, o que pode aumentar a efetividade das condutas diagnósticas. A capacitação dos profissionais de saúde que atuam em muitos desses municípios também pode influenciar na efetividade do diagnóstico. 
Os fatores geográficos são, possivelmente, influenciadores para uma menor disseminação do vírus na Amazônia, principalmente nos pequenos e médios centros urbanos, como Macapá. Esses fatores, aliados a medidas governamentais de afastamento social da população, investimentos em prevenção e conscientização e em pesquisas/desenvolvimento científico voltado para o combate a COVID-19 são essenciais para reduzir o impacto agudo no sistema público de saúde, que, na maioria desses centros urbanos, é frágil, devido a desigualdade histórica entre as regiões brasileiras, para esse tipo de epidemia.

\section{AGRADECIMENTOS}

Agradecemos a colaboração de João Silvestre da Silva-Júnior, doutor em Saúde Pública pela Faculdade de Saúde Pública da Universidade de São Paulo e de Virgílio Amaral da Cunha Junior, jornalista formado pela Universidade Federal de Viçosa.

\section{REFERÊNCIAS}

AP. Governo do Estado do Amapá. Decreto n 1.414 de 19 de Março de 2020. Dispõe sobre medidas de restrição de aglomeração de pessoas com a finalidade de reduzir os riscos de transmissão do novo Coronavírus (COVID-19) e adota outras providências. Macapá, AP: 2020.

ATLAS BRASIL. Atlas do Desenvolvimento Humano no Brasil. Disponível em: < http://atlasbrasil.org.br/2013/pt/consulta/ >. Acesso em: 24 março 2020.

BRASIL. Ministério da Saúde. Secretaria de Atenção Primária à Saúde. Protocolo de Manejo Clínico do Coronavírus (Covid-19) na Atenção Primária à Saúde. 1. ed. Brasília, DF: Ministério da Saúde - Secretaria de Atenção Primária à Saúde. 2020 a.

Ministério da Saúde. Secretaria de Vigilância em Saúde. Boletim Epidemiológico 02: Infecção humana pelo Novo Coronavírus (2019-nCov).

RC: 48443

Disponível em: https://www.nucleodoconhecimento.com.br/saude/covid-19-emmacapa 
Brasilia, DF: Ministério da Saúde - Centro de Operações de Emergências em Saúde Pública (COE-nCoV): 2020b.

- Ministério da Saúde. Secretaria de Atenção Especializada à Saúde. Protocolo de Tratamento do Novo Coronavírus (2019-nCoV). 1. ed. Brasília, DF: Ministério da Saúde - Secretaria de Atenção Especializada à Saúde. 2020c.

. Ministério da Saúde. Coronavírus: 25 mortes e 1.546 casos confirmados. Brasilia, DF: 2020d. Disponível em: < https://www.saude.gov.br/noticias/agencia-saude/46573-coronavirus-25-mortes-e-1546-casos-confirmados >. Acesso em: 23 Março 2020.

Ministério da Saúde. Portaria no 454, de 20 de Março de 2020. Declara, em todo o território nacional, o estado de transmissão comunitária do Coronavírus (Covid-19). Brasília, DF: 2020e. Disponível em: < http://www.in.gov.br/en/web/dou/-/portaria-n-454-de-20-de-marco-de-2020249091587 >. Acesso em: 24 Março 2020.

Instituto Brasileiro de Geografia e Estatística. IBGE Cidades e Estados. 2020f. Disponível em: < https://www.ibge.gov.br/cidades-e-estados >. Acesso em: 23 Março 2020.

Ministério da Saúde. DATASUS. Cadastro Nacional dos Estabelecimentos de Saúde do Brasil - CNES. Quantidade por Tipo de Prestador segundo Capital. Brasília, DF: 2020g. Disponível em: < https://nam10.safelinks.protection.outlook.com/?url=http\%3A\%2F\%2Ftabnet.datasus .gov.br\%2Fcgi\%2Ftabcgi.exe\%3Fcnes\%2Fcnv\%2Festabbr.def\&amp;data=02\%7C01 \%7C\%7C5789bcef877546b7609e08d7d5ac6237\%7C84df9e7fe9f640afb435aaaaaa aaaaaa\%7C1\%7C0\%7C637212808662483071\&amp;sdata=AZP0PC\%2BzxxMGbM TJLdlJO0zLGtXCF9F3BthmFJnvqgo\%3D\&amp;reserved=0 >. Acesso em 24 Março 2020.

RC: 48443

Disponível em: https://www.nucleodoconhecimento.com.br/saude/covid-19-emmacapa 
- Ministério da Saúde. Secretaria de Vigilância em Saúde. Boletim Epidemiológico 05: Doença pelo Coronavírus 2019. Brasilia, DF: Ministério da Saúde - Centro de Operações de Emergências em Saúde Pública (COE-nCoV): $2020 \mathrm{~h}$.

Ministério da Saúde. Sobre a doença. Brasília, DF: 2020i. Disponível em: < https://coronavirus.saude.gov.br/sobre-a-doenca >. Acesso em: 03 Abr. 2020.

Agência Nacional de Aviação Civil. Consulta Interativa - Indicadores do Mercado de Transporte Aéreo. Brasília, DF: 2020j. Disponível em: < https://www.anac.gov.br/assuntos/dados-e-estatisticas/mercado-de-transporteaereo/consulta-interativa/demanda-e-oferta-origem-destino >. Acesso em: 23 Mar. 2020

Instituto Brasileiro de Geografia e Estatística. Pesquisa Nacional por Amostra de Domicílios Contínua - PNAD Contínua 2016-2018, Características Gerais dos Moradores. Brasília, DF: 2018a. Disponível em: < https://www.ibge.gov.br/estatisticas/sociais/populacao/17270-pnadcontinua.html?edicao=24437\&t=downloads >. Acesso em: 24 Março 2020.

Ministério da Economia. Relação Anual de Informações Sociais: Amapá 2018. Brasília, DF: 2018b. Disponível em: < http://pdet.mte.gov.br/rais?view=default >. Acesso em: 03 Abril 2020.

Instituto Brasileiro de Geografia e Estatística. Coordenação de População e Indicadores Sociais. Síntese de Indicadores Sociais 2018: Uma Análise das Condições de Vida da População Brasileira. Brasília, DF: 2018c.

. Instituto Brasileiro de Geografia e Estatística. Amazônia Legal: Municípios da Amazônia Legal. Brasília, DF: 2014. Disponível em: < https://www.ibge.gov.br/geociencias/informacoes-ambientais/geologia/15819amazonia-legal.html?=\&t=acesso-ao-produto >. Acesso em: 24 Março 2020.

RC: 48443

Disponível em: https://www.nucleodoconhecimento.com.br/saude/covid-19-em$\underline{\text { macapa }}$ 
. Instituto Brasileiro de Geografia e Estatística - IBGE. Atlas de Saneamento

Glossário. Brasília., DF: 2011. Disponível em: https://biblioteca.ibge.gov.br/visualizacao/livros/liv53096_glossario_equipetec.pdf. Acesso em: 29 Mar. 2020.

. Ministério da Saúde. Guia de Vigilância Epidemiológica. Brasília, DF:. 2009. Disponível em: https://bvsms.saude.gov.br/bvs/publicacoes/guia_vigilancia_epidemiologica_7ed.pdf. Acesso em: 01 abr. 2020.

CAMPELlO, T.; GENTILI, P.; RODRIGUES, M.; HOEWELL, G.R. Faces da desigualdade no Brasil: um olhar sobre os que ficam para trás. Saúde em Debate. v.42 n. especial p.54-66, 2018. https://doi.org/10.1590/0103-11042018S305

CASCELLA, M.; RAJNIK, M.; CUOMO, A.; DULEBOHN, S.; DI NAPOLI, R. Features, Evaluation and Treatment Coronavirus (COVID-19). [Atualizado em 8 março 2020] Treasure Island, FL: StatPearls Publishing; 2020. Disponível em: <https://www.ncbi.nlm.nih.gov/books/NBK554776/ > Acesso em: 23 Março 2020.

DOREMALEN, N.V. et al. [Correspondece]. Aerosol and Surface Stability of SARSCoV-2 as Compared with SARS-CoV-1. Destinatário: The New England Journal of $\begin{array}{llll}\text { Medicine. } & \text { Massachusetts, } & 17 & \text { de }\end{array}$ https://doi.org/10.1056/NEJMc2004973

DRUMMOND, J.A. Investimentos privados, impactos ambientais e qualidade de vida num empreendimento mineral amazônico: o caso da mina de manganês de Serra do Navio (Amapá). História, Ciências, Saúde-Manguinhos. Rio de Janeiro, v. 6, supl. p. 753-792, 2000. https://doi.org/10.1590/S0104-59702000000500002

FAN, J.; LIU, X.; PAN.; DOUGLAS, M.W.; BAO, S. Epidemiology of 2019 Novel Coronavirus Disease-19 in Gansu Province, China, 2020. Emerging Infectious Diseases. v. 26 n.6, 2020a. https://doi.org/10.3201/eid2606.200251 
FAN, C. et al. Prediction of Epidemic Spread of the 2019 Novel Coronavirus Driven by Spring Festival Transportation in China: A Population-Based Study. International Jornal of Envirommental Research and Public Health. v.17 n.5, $2020 \mathrm{~b}$. https://doi.org/10.3390/ijerph17051679

FARIA, N.R. et al. Genomic and epidemiological monitoring of yellow fever virus transmission potential. Science. v.361 n. 6405 p.894-899, 2018. https://doi.org/10.1126/science.aat7115

GALLASCH, C.H.; CUNHA, M.L.; PEREIRA, L.A.S.; SILVA-JUNIOR J.S. Prevenção relacionada à exposição ocupacional do profissional de saúde no cenário de COVID19. Revista Enfermagem UERJ. v. 28 e. 49596. https://doi.org/10.12957/reuerj.2020.49596

GIOVANETTI, M. et al. Genomic and Epidemiological Surveillance of Zika Virus in

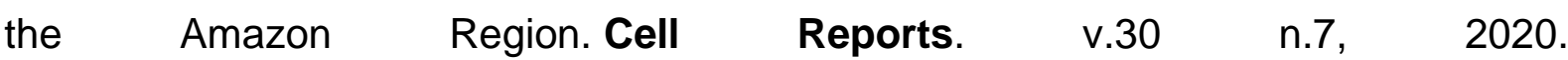
https://doi.org/10.1016/j.celrep.2020.01.085

HAFFAJEE, R.L.; MELLO, M.M. Thinking Globally, Acting Locally: The U.S. Response to Covid-19. The New England Journal of Medicine, 2020. https://doi.org/10.1056/NEJMp2006740

KAMPF, G.; TODT, D.; PFAENDER, S.; STEINMANN, E. Persistence of coronaviruses on inanimate surfaces and their inactivation with biocidal agents. The Journal of Hospital Infection. v. 104, n. 3, p. 246-251, 2020. https://doi.org/10.1016/j.jhin.2020.01.022

KUCHARSKI, A.J. et al. Early dynamics of transmission and control of COVID-19: a mathematical modelling study. The Lancet: Infectous Diseases. 11 Março 2020. https://doi.org/10.1016/S1473-3099(20)30144-4

$\mathrm{KOH}$, D. Occupational risks for COVID-19 infection. Occupational Medicine. v.70 n.1 p. 3-5, 2020. https://doi.org/10.1093/occmed/kqaa036

RC: 48443

Disponível em: https://www.nucleodoconhecimento.com.br/saude/covid-19-em$\underline{\text { macapa }}$ 
LAI, S.; BOGOCH, I.I.; WALTS, E.; KHAN, K.; LI, Z.; TATEM, A. Preliminary risk analysis of 2019 novel coronavirus spread within nad beyond China. World pop. No prelo, 2020.

Disponível em:

https://www.worldpop.org/resources/docs/china/WorldPop-coronavirus-spread-riskanalysis-v2.pdf >. Acesso: 02 Abril 2020.

LEVIN J.; FOX J.A.; FORDE D.R. Elementary statistics in social research. $12^{a}$ ed. Upper Saddle River: Pearson Education; 2014.

LEVORATO, C.D.; MELLO, L.M.; SILVA, A.S.; NUNES A.A. Fatores associados à procura por serviços de saúde numa perspectiva relacional de gênero. Ciência e Saúde Coletiva. v. 19 n.4 p. 1263-74, 2020. https://doi.org/10.1590/141381232014194.01242013

LIPSITCH, M.; PHIL, D.; SWERDLOW, D.L.; FINELLI, L. Defining the Epidemiology of Covid-19 - Studies Needed. The New England Journal of Medicine. 2020. https://doi.org/10.1056/NEJMp2002125

$\mathrm{LI}, \mathrm{W}$. et al. Angiotensin-converting enzyme 2 is a functional receptor for the SARS coronavirus. Nature. v. 426, 2003. https://www.nature.com/articles/nature02145.pdf

LI, Y.C.; BAI W.Z.; HASHIKAWA, T. The neuroinvasive potential of SARS-CoV2 may be at least partially responsible for the respiratory failure of COVID-19 patients. Journal of Medical Virology. p. 1-4, 2020. https://doi.org/10.1002/jmv.25728

MAPA DO CORONA VÍRUS. POLATO, A.; CUNHA, R.; SORANO, V. (Coord.). Casos de coronavírus no Brasil e no Mundo: mapa e evolução. Disponível em: < https://especiais.g1.globo.com/bemestar/coronavirus/mapacoronavirus/?_ga=2.48817062.1083509909.15847872161227695381.1584787197\#/.> Acesso em: 26 mar. 2020. 
MCINTOSH, K. UpToDate. Coronavirus Disease 2019 (COVID-19). USA: 2020. Disponível em: < https://www.uptodate.com/contents/coronavirus-disease-2019covid-19 >. Acesso em: 23 março 2020.

NASSIRI, R. Perspective on Wuhan Viral Pneumonia. Advances in Public Health, Community and Tropical Medicine, V. 02, 2020.

OLIVEIRA, N.M.; PIFFER, M.; STRASSBURG, U. O Indicador de Desenvolvimento Regional no Território do Tocantins. Interações. v.20 n.1 p. 3-20, 2019. http://dx.doi.org/10.20435/inter.v0i0.1607

OLIVEIROS, B.; CARAMELO, L.; FERREIRA, N.C.; CARAMELO, F. Role of temperature and humidity in the modulation of the doubling time of COVID-19 cases. Medrxiv. 2020. https://doi.org/10.1101/2020.03.05.20031872

PREM, K. et al. The effect of control strategies to reduce social mixing on outcomes of the COVID-19 epidemic in Wuhan, China: a modelling study. The Lancet. 25 Março 2020. https://doi.org/10.1016/S2468-2667(20)30073-6

READ, J.M.; BRIDGEN, J.R.E.; CUMMINGS, D.A.T.; HO, A.; JEWELL, C.P. Novel coronavirus 2019-nCoV: early estimation of epidemiological parameters and epidemic predictions. Medrxiv. No prelo, 2020. https://doi.org/10.1101/2020.01.23.20018549

RIPAP. Rede Integrada de Pesquisa do Amapá. Carta Manifesto da Comunidade Científica Amapaense. Macapá. 2020. Disponível em: < https://drive.google.com/file/d/1Kgsikv5B27v60QPyRR6gpyEVjmnVOVfF/view >. Acesso em: 03 abr. 2020.

ROSA, S.J. Transporte e Exclusão Social: A Mobilidade da População de Baixa Renda da Região Metropolitana de São Paulo e Trem Metropolitano. 2006. Dissertação (Mestrado em Engenharia) - Escola Politécnica da Universidade de São Paulo, São Paulo, 2006. Disponível em: 
https://www.teses.usp.br/teses/disponiveis/3/3138/tde-07122006-

163515/publico/dissertacao_silvio_jose_rosa.pdf. Acesso em: 04 abr. 2020.

ROTHAN, H.A.; BYRAREDDY, S.N. The epidemiology and pathogenesis of coronavirus disease (COVID-19) outbreak. Journal of Autoimmunity. No prelo, 2020. https://doi.org/10.1016/j.jaut.2020.102433

ROTHE, C. et al., [Correspondece]. Transmission of 2019-nCoV Infection from an Asymptomatic Contact in Germany. Destinatário: The New England Journal of Medicine. Massachusetts, 5 de Março, 2020. https://doi.org/10.1056/NEJMc2001468

SESACE. Governo do Estado do Ceará. Secretaria de Saúde. Boletim epidemiológico: Doença pelo novo coronavírus (COVID-19) n 18 . Fortaleza, CE: 2020.

SESAMA. Governo do Estado do MaranhãO. Secretaria de Saúde. Nota 9 - SES monitora 205 casos suspeitos de COVID-19. São Luís, MA: 2020.

SESAMT. Governo do Estado do Mato Grosso. Secretaria de Saúde. Secretaria Adjunta de Atenção e Vigilância em Saúde. Nota Informativa 16 COVID-19. Cuiabá, MT: 2020.

SESAMG. Governo do Estado de Minas Gerais. Secretaria de Estado de Saúde de Minas Gerais. Subsecretaria de Vigilância em Saúde. Centro de Operações de Emergência em Saúde Pública. Boletim Informativo Diário de 20/03/2020. Belo Horizonte, MG: 2020a.

SESAMG. Governo do Estado de Minas Gerais. Secretaria de Estado de Saúde de Minas Gerais. Subsecretaria de Vigilância em Saúde. Centro de Operações de Emergência em Saúde Pública. Boletim Informativo Diário de 14/03/2020. Belo Horizonte, MG: 2020b. 
SESAMG. Governo do Estado de Minas Gerais. Secretaria de Estado de Saúde de Minas Gerais. Subsecretaria de Vigilância em Saúde. Centro de Operações de Emergência em Saúde Pública. Informe Epidemiológico n³, de 03 de Março de 2020. Belo Horizonte, MG: 2020c.

SESARS. Governo do Estado do Rio Grande do Sul. Secretaria de Saúde. Centro Operações de Emergências Rio Grande do Sul. Informe Epidemiológico - COVID19 EM 19/03/2020. Porto Alegre, RS: 2020.

SILVA, D.R.; VIANA, V.P.; MÜLLER, A.M.; LIVI, F.P.; DALCIN, P.T.R. Respiratory viral infections and effects of meteorological parameters and air pollution in adults with respiratory symptoms admitted to the emergency room. Influenza and others respiratory viruses. v. 8 n. 1, 2013. https://doi.org/10.1111/irv.12158

TORMAN, V.B.L.; COSTER, R.; RIBOLDI, J. Normalidade de variáveis: métodos de verificação e comparação de alguns testes não-paramétricos por simulação. Revista HCPA. Porto Alegre, v. 32, n. 2, p. 227-234, 2012.

TRAVASSOS C.; OLIVEIRA E.X.G.; VIACAVA F. Desigualdades geográficas e sociais no acesso aos serviços de saúde no Brasil: 1998 e 2003. Ciência \& Saúde Coletiva. v. 11 n. 4 p. $975-986$, 2006. https://doi.org/10.1590/S141381232006000400019

VELAVAN, T.P.; MEYER, C.G. The COVID-19 epidemic. Tropical Medicine \& International Health. v. 25, n.3, 2020. https://doi.org/10.1111/tmi.13383

VIANA, A.L.D.; IBAÑEZ, N.; ELIAS, P. E. M. Saúde, desenvolvimento e território. 1 ed. São Paulo: Hucitec; 2009.

WANG, J.; TANG, K.; FENG, K.; LV.W. High Temperature and High Humidity Reduce the Transmission of COVID-19. SSRN. 2020. https://dx.doi.org/10.2139/ssrn.3551767 
WHO. Word Health Organization. Report of the WHO-China Joint Mission on Coronavirus Disease 2019 (COVID-19). China: Word Health Organization - The Joint Mission. 2020a. Disponível em: < https://www.who.int/docs/defaultsource/coronaviruse/who-china-joint-mission-on-covid-19---final-report-1100hr28feb2020-11 mar-update.pdf?sfvrsn=1a13fda0_2\&download=true >

WHO. World Health Organization. Coronavirus disease 2019 (COVID-19): Situacional Report - 62. Genebra, Switzerland. WHO: 2020b.

WHO. World Health Organization. Coronavirus disease 2019 (COVID-19): Situacional Report - 38. Genebra, Switzerland. WHO: 2020c.

WU, J.T.; LEUNG, K.; LEUNG, G.M.; Nowcasting and forecasting the potential domestic and international spread of the 2019-nCoV outbreak originating in Wuhan, China: a modelling study. The Lancet. v. 395 n. 10225 p. 689-697, 2020. https://doi.org/10.1016/S0140-6736(20)30260-9

ZASLAVSKY, R.; GOULART, B. N. G. Migração pendular e atenção à saúde na região de fronteira. Ciência e Saúde Coletiva. 2017, vol.22, n.12. https://doi.org/10.1590/1413-812320172212.03522016

ZHANG, Y. et al. The Novel Coronavirus Pneumonia Emergency Response Epidemiology Team. The epidemiological characteristics of an outbreak of 2019 novel coronavirus diseases (COVID-19) in China. China CDC Weekly. v. 2, n. X, 2020. https://doi.org/10.3760/cma.j.issn.0254-6450.2020.02.003

Enviado: Abril, 2020.

Aprovado: Abril, 2020. 